\title{
FONTES ALTERNATIVAS DE NUTRIENTES PARA O CULTIVO DE Arthrospira (Spirulina) spp.
}

Esta revisão de literatura teve como objetivo reunir informações sobre fontes alternativas de nutrientes para o cultivo de microalgas do gênero Arthrospira (Spirulina), bem como o uso de bases alternativas de baixo custo para essa finalidade, uma vez que o meio de cultura constitui parte significativa dos custos de produção. Essas atividades estão ainda aliadas a benefícios ambientais, pois o cultivo de microalgas também constitui medida para remoção de nitratos e fosfatos de resíduos oriundos de diversas naturezas. Concluiu-se que ampla variedade de fontes alternativas de nutrientes pode ser aplicada sem perda de produtividade, desde que cada nutriente esteja ajustado à sua taxa de utilização pela microalga, e que os resíduos empregados como base tenham suas deficiências ou excessos de nutrientes corrigidos.

* Mestre em Ciência dos Alimentos, Departamento de Ciência e Tecnologia de Alimentos, Universidade Federal de Santa Catarina (UFSC), Florianópolis, SC (e-mail: miguelp_sc@yahoo.com.br).

** Doutora em Ciência dos Alimentos, Departamento de Ciência e Tecnologia de Alimentos, UFSC, Florianópolis, SC (e-mail: rcotorres@gmail.com).

*** Doutor em Ciência dos Alimentos, Professor titular, Departamento de Ciência e Tecnologia de Alimentos, UFSC, Florianópolis, SC (e-mail: ernanis@cca.ufsc.br). 


\section{INTRODUÇÃO}

O termo microalgas aplica-se à ampla variedade de microrganismos fotossintéticos, produtores de clorofila a, apresentando dessa forma metabolismo análogo ao das plantas. Sob esta denominação incluem-se organismos com dois tipos de estrutura celular: os procarióticos, com representantes na divisão Cyanophyta (cianobactérias) e os eucarióticos, com representantes das divisões Chlorophyta, Euglenophyta, Rhodophyta, Haptophyta (Prymnesiophyta), Heterokontophyta (Bacillariophyceae, Chrysophyceae e Xantophyceae), Cryptophyta e Dinophyta (DERNER et al., 2006). Considerando a grande biodiversidade de microalgas, esse grupo representa fonte promissora de novos produtos com aplicação nas indústrias alimentícia e farmacêutica, podendo atender às altas demandas desses setores mediante desenvolvimento de técnicas de cultivo (PULZ e GROSS, 2004).

Segundo Becker (2004), as principais microalgas cultivadas comercialmente são as espécies Dunaliella salina (Chlorophyceae) para a obtenção de 2-caroteno; Haematococcus pluvialis (Chlorophyceae) para a obtenção de astaxantina; e espécies dos gêneros Chlorella (Chlorophyceae) e Arthrospira (Cyanophyceae) para a adição em alimentos naturais ("health food").

A classificação de Arthrospira e Spirulina em gêneros distintos é adotada pelo Manual de Berguey e confirmada com base em características morfológicas e genéticas. As espécies $A$. platensis e A. máxima são as de maior interesse comercial. Embora a biomassa de Arthrospira produzida comercialmente ainda receba a denominação de Spirulina (ARAÚJO, FACCHINETTI e SANTOS 2003).

Espécies do gênero Arthrospira apresentam em sua composição bioquímica, elevadas concentrações de proteína unicelular e de aminoácidos essenciais, ressaltando sua importância para a indústria alimentícia. As propriedades farmacológicas de substâncias como o ácido ${ }^{3}$-linolênico e polissacarídeos também indicam um grande potencial para o uso terapêutico. São citados resultados benéficos na estimulação do sistema imunológico e da microbiota intestinal; inibição da replicação viral; contra a hiperlipidemia, hipercolesterolemia, tumor bucal, hipertensão, obesidade, diabetes e efeitos tóxicos de radiações, atribuindo a esta cianobactéria um conjunto de propriedades que dificilmente podem ser encontradas simultaneamente em um único produto natural (BERTOLDI et al. e ARAÚJO 2008; ARAÚJO, 2003). Sua produção em massa teve início na década de 1970 , sendo que $70 \%$ da produção mundial destina-se ao consumo humano. Concomitante à sua produção em massa, pesquisas foram realizadas a fim de determinar o efeito das condições ambientais e do meio de cultura na produtividade e na obtenção de produtos químicos de interesse (MATSUDO et al., 2009).

Estudos sobre a nutrição de microalgas permitem avaliar o papel dos vários elementos químicos no seu crescimento e produtividade. São de fundamental importância para a viabilização dos cultivos de algas, pois definem os componentes que devem ser acrescentados em maiores ou menores quantidades nos meios de cultura para proporcionar melhor desenvolvimento das espécies. Também possibilita identificar os componentes efetivamente desnecessários para determinada espécie, podendo ser removido do meio de cultura sem qualquer prejuízo à microalga e acarretando economia ao cultivador (LOURENÇO, 2006). Os ensaios de adição de nutrientes, em que se detectam mudanças sutis nas concentrações dos elementos de um meio de cultura no crescimento da microalga, fornecem informações importantes sobre o efeito de cada nutriente, tanto na sua cinética de crescimento quanto na composição bioquímica da biomassa produzida (CAMACHO e WIT, 2003).

O carbono é o elemento necessário em maior concentração por ser constituinte de todas as substâncias orgânicas sintetizadas pelas células (proteínas, carboidratos, ácidos nucléicos, vitaminas e lipídios, entre outros) (LOURENÇO, 2006). A fotossíntese constitui a principal rota de fixação do carbono, entretanto algumas espécies (incluindo o gênero Arthrospira) permitem a combinação entre a fotossíntese e a assimilação heterotrófica de compostos orgânicos. Tal processo, denominado mixotrofia, possibilita que o crescimento das microalgas não seja estritamente dependente da intensidade de luz nos cultivos (CHOJNACKA e NOWORYTA, 2004), bem como o uso de variadas fontes de carbono dependendo da aplicação da biomassa produzida e dos recursos disponíveis. 
O nitrogênio constitui componente fundamental de três classes de substâncias estruturais e do metabolismo primário das células: proteínas, ácidos nucléicos e pigmentos fotossintetizantes (clorofilas e ficobilinas). Suprimento abundante de nitrogênio no cultivo gera tendência de aumento nos teores de proteína e clorofila nas células. Em baixas concentrações diminuem os teores dessas duas substâncias, reduzindo drasticamente também a taxa de divisão celular. A concentração de ácido linolênico aumenta, mas o conteúdo de ácidos graxos permanece constante. Também ocorre aumento na concentração de polissacarídeos nas células e as ficocianinas são degradadas e utilizadas como fonte de nitrogênio. Mais carotenóides e menos clorofilas são produzidas nessas condições, gerando mudanças de cor no meio de cultivo que tendem ao amarelado (COLLA, BERTOLIN e COSTA 2004; LOURENÇO, 2006; FERREIRA, 2008). Apesar da ampla utilização dos sais de nitrato, estudos mostram muita variedade de fontes alternativas de nitrogênio.

Visando a produção mais custo efetiva, aliada a benefícios ambientais, vários estudos demonstram a eficiência do uso de diferentes bases para este fim. Tais bases geralmente são deficientes em componentes que precisam ser ajustados mediante testes específicos para determinar quais componentes devem ser utilizados com as espécies de interesse.

O objetivo desta revisão foi reunir informações sobre fontes alternativas de nutrientes para o cultivo de microalgas do gênero Arthrospira (Spirulina), uma vez que o meio de cultura constitui parte significativa dos custos de produção.

\section{FONTES DE CARBONO}

O bicarbonato, fonte de carbono mais frequentemente utilizada em meios de cultura, é incorporado ativamente gerando gasto energético nesse processo. É convertido em $\mathrm{CO}_{2}$, utilizado na fotossíntese, e em carbonato, que é liberado para o meio extracelular aumentando o pH do cultivo (MATSUDO, 2006). O gênero Arthrospira necessita de grande quantidade de bicarbonato, que além de fonte de carbono, auxilia a manter a condição alcalina do meio de cultura, vital para o cultivo desse gênero e constitui barreira para o desenvolvimento de outros micro-organismos. $\mathrm{O}$ uso de bicarbonato de sódio de grau comercial não alterou significativamente a produção de biomassa, o conteúdo de clorofila e de proteínas quando comparado com o de grau analítico (RAOOF, KAUSHIK e REINHER, 2006) constituindo estratégia viável para produções em larga escala. Segundo Laliberté, Olguín e La Noue (1997), a suplementação de carbono representa grande parte dos custos e embora tradicionalmente apliquem-se concentrações entre 9 e $17 \mathrm{~g} \cdot \mathrm{L}^{-1}$ de bicarbonato, alguns trabalhos demonstram que a utilização de 3 a 4 g.L.-1 é suficiente.

O dióxido de carbono $\left(\mathrm{CO}_{2}\right)$ constitui a fonte preferida de carbono pelas microalgas, uma vez que se difunde passivamente do meio de cultura ao meio intracelular, sendo utilizado diretamente nos processos de fixação de carbono (DERNER, 2006). Na aquicultura assume grande interesse visto que - $\mathrm{CO}_{2}$ utilizado pode ser proveniente de atividades industriais, produzido a partir da queima de combustíveis fósseis e contribuindo para a redução das emissões desse gás associado ao efeito estufa. Segundo Soletto e colaboradores (2008), a taxa de alimentação de $\mathrm{CO}_{2}$ de $0,44 \mathrm{~g} \cdot \mathrm{L}^{-1} \cdot \mathrm{d}^{-1}$ conferiu melhores resultados na produtividade de $A$. platensis.

O melaço, resíduo do processamento da cana-de-açúcar, é utilizado na produção de álcool e vinagre, na alimentação animal e na adubação do solo. Os carboidratos representam mais de $50 \%$ de sua composição, o que the confere grande potencial como fonte alternativa de carbono para a suplementação de meios de cultivo para microalgas (ANDRADE e COSTA, 2008). Seu efeito no crescimento de $A$. platensis é mais evidente após 11 dias de cultivo, pois antes desse período a intensidade de luz mostrou-se mais influente no desenvolvimento da microalga (ANDRADE e COSTA, 2007).

Pesquisas empregando glicose, carboidrato mais abundante na biomassa do gênero Arthrospira, demonstraram a alta eficiência desse composto que proporcionou velocidade específica de crescimento 
de $0,096 \mathrm{~d}^{-1}$ de biomassa (LODI et al., 2005). Segundo Muliterno e colaboradores (2005), a concentração de glicose de $0,5 \mathrm{~g} \cdot \mathrm{L}^{-1}$ adicionada no meio de Zarrouk diluído a $75 \%$ em água destilada, sob modo de cultivo em batelada alimentada, resultou na produção de biomassa de $5,38 \mathrm{~g} \cdot \mathrm{L}^{-1}$. Chen e colaboradores (2006) afirmaram que o uso dessa fonte de carbono aumentou a concentração de ficocianinas de 0,119 g. $\mathrm{L}^{-1}$ no tratamento controle para: $0,279 \mathrm{~g} \cdot \mathrm{L}^{-1}$ no meio suplementado com $2,0 \mathrm{~g} \cdot \mathrm{L}^{-1}$ de glicose, as aloficocianinas de $0,042 \mathrm{~g} \cdot \mathrm{L}^{-1}$ para $0,126 \mathrm{~g} \cdot \mathrm{L}^{-1}$ e a biomassa de $1,08 \mathrm{~g} \cdot \mathrm{L}^{-1}$ para $2,57 \mathrm{~g} \cdot \mathrm{L}^{-1}$. Chen e Zang (1997) registraram aumento de mais de cinco vezes na produção de biomassa cultivada com glicose, quando comparada com a produção fotoautotrófica de $A$. platensis.

$\mathrm{O}$ acetato tem sido estudado como potencial fonte de carbono, uma vez que pesquisas demonstraram seu efeito para aumentar tanto a biomassa de espécies de microalgas (Haematococcus pluvialis, Dunaliella salina) e fungos (Phaffia rhodozyma), quanto o seu teor de carotenos. Isso pode ser explicado pelo fato do ácido acético ser precursor dos carotenóides (MOJAAT et al. 2008). Segundo Chen e colaboradores (2006), o uso de acetato na concentração de 4,0 g. $\mathrm{L}^{-1}$ aumentou a biomassa de A. platensisde de $1,08 \mathrm{~g} \cdot \mathrm{L}^{-1}$ para $1,65 \mathrm{~g} \cdot \mathrm{L}^{-1}$. Lodi e colaboradores (2005) obtiveram velocidade de crescimento específica de $0,074 \mathrm{~d}^{-1}$ utilizando essa fonte de carbono. No mesmo trabalho foi citada a utilização de propionato, resultando em velocidade específica de crescimento de $0,068 \mathrm{~d}^{-1}$ de biomassa de A. platensis.

\section{FONTES DE NITROGÊNIO}

Os sais de nitrato $\left(\mathrm{NaNO}_{3}, \mathrm{KNO}_{3}\right.$ ) são as fontes de nitrogênio que proporcionam maior produção de biomassa, justificando a sua aplicação nos meios Paoletti, Zarrouk e Schlosser (SASSANO et al., 2007). Segundo Colla e colaboradores (2007) a produtividade de A. platensis permanece inalterada sob variação da concentração de nitrato de sódio no intervalo de $0,625 \mathrm{~g} \cdot \mathrm{L}^{-1}$ a 2,5 g. $\mathrm{L}^{-1}$; mantendo-se o cultivo a $30^{\circ} \mathrm{C}$, resultado também relatado por El-Baky, El-Baz e El-Baroty (2008). Esses estudos demonstraram que a quantidade desse composto pode ser reduzida para aproximadamente $25 \%$ da concentração aplicada no meio de Zarrouk, sem perdas de produção. Entretanto, Çelekli e Yavuzatmaca (2009) constataram que a concentração de nitrato de sódio de 2,5 g.:-1 resultou em maior produtividade frente à utilização de 2,0 g.L.-1. El-Baky, El-Baz e El-Baroty (2008) acrescentaram que a aplicação de $1,875 \mathrm{~g} \cdot \mathrm{L}^{-1}$ de nitrato de sódio, mantendo a cultura a $35^{\circ} \mathrm{C}$ diminui a produtividade, mas confere maiores concentrações de proteínas, lipídios e compostos fenólicos à biomassa produzida.

Com o intuito de verificar a eficiência de fontes de nitrogênio de menor custo, o efeito de sais de amônio na produção de biomassa de $A$. platensis foi avaliado. $O$ cloreto de amônio gerou resultados ainda melhores que os obtidos com nitratos em cultivos em tanques abertos, possibilitando a utilização dessa microalga no tratamento de resíduos para remoção de compostos nitrogenados Sassano et al. (2007). O uso dessa fonte de nitrogênio também aumentou o teor de ácidos graxos totais (MANABE et al., 1992). Converti e colaboradores (2006) afirmaram que a concentração de 1,7 mM de cloreto de amônio resultou na produtividade máxima de biomassa e de assimilação de nitrogênio, enfatizando a rapidez com que a biomassa de $A$. platensis assimila o cloreto de amônio. Tal composto foi assimilado ainda mais facilmente do que a uréia, outro nutriente de difusão celular facilitada, mas que precisa ser previamente hidrolisado a amônia. Já o cloreto de amônio é diretamente metabolizado pela enzima glutamina sintetase.

Soletto e colaboradores (2005) estudaram o efeito de diferentes concentrações de sulfato de amônio e constataram que na concentração de $1,1 \mathrm{mM}$, uma cepa de $A$. platensis apresentou crescimento satisfatório após 5 dias $\left(0,640 \mathrm{~g} \cdot \mathrm{L}^{-1}\right)$. A concentração de $1,7 \mathrm{mM}$ causou inibição de crescimento após 2 dias de cultivo. Porém nesse estudo, a uréia foi aplicada sob essas mesmas concentrações e a biomassa produzida mostrou-se praticamente o dobro da produzida com sulfato de amônio. Segundo Ferreira (2008) a assimilação de nitrogênio é facilitada com a utilização de sulfato de amônio que se dissocia no meio de cultura gerando amônia, a forma de nitrogênio preferencial de $A$. platensis. 
Assim como os sais de amônio, a uréia também é utilizada com intuito de baixar os custos da produção. O seu emprego apresenta, no entanto, os mesmos pontos negativos, pois sua hidrólise a amônia sob condições alcalinas gera perda de nutriente por volatilização, sendo a produção também afetada pelo efeito tóxico desse composto. Por isso, a aplicação desses nutrientes na produção em massa exige controle de adição (MATSUDO et al. 2009). Segundo Danesi e colaboradores (2002), o melhor protocolo para adição de uréia em tanque de 5 litros é a massa inicial de $0,4 \mathrm{~g}$, seguida de adição contínua por 14 dias até alcançar massa total adicionada de 2,5 g. Devem ser evitados protocolos de adição com intervalos de 48 horas, que geraram os piores resultados, e a temperatura do cultivo precisa ser considerada. $\mathrm{A} 33^{\circ} \mathrm{C}$ ocorre queda na produção devido à alta evaporação de amônia e à perda de água, também por evaporação, causando danos às células decorrentes da alteração da pressão osmótica no meio de cultura. Rangel-Yagui et al. (2004) demonstraram mediante metodologia de superfície de resposta que a concentração de uréia de $0,5 \mathrm{~g} \cdot \mathrm{L}^{-1}$ resultou em maior produção. A massa inicial adicionada foi de $0,08 \mathrm{~g} \cdot \mathrm{L}^{-1}$.

\section{MEIOS DE CULTURA À BASE DE ÁGUA DO MAR}

Embora as concentrações de nutrientes dissolvidos na água do mar sejam presumivelmente baixas, elas não são determinadas. Como as concentrações dos nutrientes adicionados ao meio de cultura são muito maiores (centenas ou milhares de vezes, dependendo do elemento químico e das características da água do mar) assume-se que as concentrações finais de nutrientes no meio de cultura correspondem essencialmente aos componentes adicionados (LOURENÇO, 2006). Ao utilizar água do mar como base para o meio de cultura, Tredici, Papuzzo e Tomaselli (1986) citam a necessidade de manutenção do $\mathrm{pH}$ entre 8,0 e 8,3 com baixa concentração de fosfatos a fim de evitar a precipitação de carbonatos e fosfatos no cultivo.

Faucher, Coupal e Leduy (1979) demonstraram que a água do mar, abrandada com 19,2 g.L-1 de bicarbonato de sódio e suplementada com $0,5 \mathrm{~g} \cdot \mathrm{L}^{-1} \mathrm{de} \mathrm{K}_{2} \mathrm{HPO}_{4}, 3,0 \mathrm{~g} \cdot \mathrm{L}^{-1}$ de $\mathrm{NaNO}_{3}$ e $0,01 \mathrm{~g} \cdot \mathrm{L}^{-1} \mathrm{de}$ $\mathrm{FeSO}_{4}$ resultou em produtividade similar a do meio de cultura sintético usado como padrão. Os mesmos resultados foram obtidos substituindo-se o nitrato por $0,2 \mathrm{~g} \cdot \mathrm{L}^{-1}$ de uréia. O emprego desse meio de cultura também foi eficiente quando aplicado em maior escala num tanque aberto de $130 \mathrm{~L}$.

Olguín e colaboradores (2001) utilizaram água do mar adicionada de $2 \%(\mathrm{v} / \mathrm{v})$ de resíduo sólido oriundo da criação de suínos, previamente tratado por digestão anaeróbica. A concentração de biomassa após 12 dias de cultivo foi similar à obtida no meio controle de Zarrouk. O teor de lipídios, polissacarídeos e de ácido ${ }^{3}$-linolênico (GLA) mostrou-se mais alto do que na biomassa obtida no meio controle, mas o teor de proteína foi consideravelmente menor. Ronda e Lele (2008) verificaram aumento na concentração de GLA aplicando alta intensidade luminosa (6 klux) e baixa temperatura $\left(25^{\circ} \mathrm{C}\right)$. Assim, é possível que o aumento na concentração de GLA obtido por Olguín e colaboradores (2001) tenha sido decorrente da utilização de meio de cultura complexo, pois empregaram baixa intensidade luminosa e temperatura relativamente alta $\left(32^{\circ} \mathrm{C}\right)$.

A maior produtividade de biomassa em meio de cultura à base de água do mar foi obtida por Olguín e colaboradores (2003) adicionando $2 \%$ de resíduo de tratamento de suínos, previamente tratado por digestão anaeróbica em água do mar não tratada. Houve suplementação de $2 \mathrm{~g} \cdot \mathrm{L}^{-1}$ de bicarbonato de sódio nos dias 0,3 e 5 . Tais autores adotaram a estratégia de produção anual, usando no inverno a profundidade do cultivo de $10 \mathrm{~cm}$ e no restante do ano entre 15 e $25 \mathrm{~cm}$, obtendo produtividade de $11,8 \mathrm{~g} \cdot \mathrm{m}^{-2} \cdot \mathrm{d}^{-1}$.

\section{5 ÁGUA DOCE}

Reinehr e Costa (2006) utilizaram água da Lagoa Mangueira, Rio Grande do Sul, suplementada com $10 \%$ do meio de Zarrouk. Tanto a velocidade específica de crescimento quanto a produtividade de 
biomassa foram similares às obtidas com o meio de Zarrouk original. O sistema de cultivo em batelada mostrou-se de duas a três vezes mais produtivo que o sistema contínuo. Costa e colaboradores (2002), utilizando água da mesma procedência, afirmaram que a concentração de 0,00585 M de uréia mostrou-se ótima para o crescimento da microalga nessas condições. Também constataram não haver necessidade da adição de bicarbonato de sódio, obtendo dessa forma 1,4 g. $\mathrm{L}^{-1}$ de biomassa após 780 horas de cultivo.

\section{EFLUENTES DE PRODUÇÃO ANIMAL}

Para utilização de efluentes provenientes da produção animal no cultivo de Arthrospira spp., geralmente é necessário tratamento prévio por digestão anaeróbica, alta diluição do resíduo, temperatura em torno de $30^{\circ} \mathrm{C}$ e suplementação com bicarbonato de sódio. A Tabela 1 mostra exemplos das condições ambientais e suplementação de nutrientes para o cultivo dessa microalga (LALIBERTÉ, OLGUÍN e LA NOUE, 1997). Segundo Cañizares-Villanueva e colaboradores (1995), a utilização desses resíduos permite que os mesmos adquiram qualidades aceitáveis para lançamento no meio ambiente após o cultivo, devido à retirada de nitratos e fosfatos pela microalga. O meio de cultura testado consistiu de $1,0 \mathrm{~kg}$ de esterco suíno diluído em 20 L de água, tratado por decantação e estabilização do sobrenadante por aeração intensa. $O$ teor de cinzas da biomassa foi elevado, apontado como consequência da alta concentração de minerais no meio de cultura, que a lavagem prévia à liofilização da biomassa não teria removido. Para possibilitar a utilização de esterco suíno é necessário diluir novamente o meio com igual volume de água destilada para reduzir a alta concentração de amônia, e como medida para clarificar o meio de cultura para favorecer a fotossíntese da microalga. A mesma medida foi adotada por Cañizares e Domínguez (1993). Bertolin e colaboradores (2005) otimizaram a diluição a ser aplicada utilizando esse resíduo e afirmaram que a diluição de $80 \%$ gerou os melhores resultados.

O crescimento e as características químicas da biomassa produzida a partir de efluentes da criação de suínos variaram conforme o modo como o resíduo foi adicionado ao cultivo. Apenas uma adição ao início do cultivo resultou em maior produtividade (10.9 g.m"2.d) e em grande variação no conteúdo de proteínas na biomassa (de 17 a 65,6\%). A adição semi-contínua do resíduo acompanhada do controle de $\mathrm{pH}$ do cultivo baixou a produtividade $\left(9,0 \mathrm{~g} \cdot \mathrm{m}^{\mathrm{n}} . \mathrm{d}\right.$ ), porém o conteúdo de proteínas das bateladas de biomassa coletadas apresentou menor variação (de 34,8 a 49,1\%), provavelmente devido a maior estabilidade no nível de nitrogênio disponível para a microalga (OLGíN et al., 1997).

Mitchell e Richmond (1988) testaram a viabilidade da utilização de resíduo sólido proveniente da criação de gado, diluído em água contendo $10 \mathrm{~g} \cdot \mathrm{L}^{-1}$ de $\mathrm{NaCl}$. O crescimento da microalga foi lento, porém a suplementação com carbono, nitrogênio e fósforo mostrou resultados similares aos obtidos com o meio sintético padrão. A aeração foi essencial para o desenvolvimento da microalga sob essas condições.

\section{RESÍDUOS DE PLANTAS INDUSTRIAIS}

Segundo Anaga e Abu (1996), o efluente de produtora de fertilizantes NPK constitui alternativa para a base de meio de cultura devido suas altas concentrações de nitrogênio, fósforo e enxofre. A biomassa de Arthorspira cultivada nessas condições foi capaz de utilizar mais de $50 \%$ dos nitratos, fosfatos e sulfatos do efluente após 21 dias de cultivo.

As condições ambientais típicas das áreas em que a dessalinização de água do mar ou continental é realizada, aliada à alta salinidade proveniente do resíduo, confere grande potencial de utilização do concentrado de dessalinização no cultivo de A. platensis (FRITZMANN et al., 2007). Volkmann e colaboradores (2008) demonstraram que a produtividade dessa microalga foi ainda mais 
alta do que no meio sintético padrão utilizado $\left(4,954 \mathrm{~g} \cdot \mathrm{L}^{-1} \mathrm{em}\right.$ meio à base de concentrado contra 2,587 g. $\mathrm{L}^{-1}$ em meio de Paoletti), aumentando também a concentração de proteínas.

\section{TABELA 1 - EXEMPLOS DE CONDIÇÕES AMBIENTAIS E SUPLEMENTAÇÃO DE NUTRIENTES PARA O CULTIVO DE Arthrospira sp. EM RESÍDUOS DE PRODUÇÃO ANIMAL}

\begin{tabular}{|c|c|c|c|c|c|c|c|c|}
\hline Espécie & $\begin{array}{l}\text { Resíduo } \\
\text { (diluição) }\end{array}$ & $\begin{array}{c}\text { Volume } \\
(\mathrm{L})\end{array}$ & $\begin{array}{c}\text { Temperatura } \\
\left({ }^{\circ} \mathrm{C}\right)\end{array}$ & Luz & $\begin{array}{l}\mathrm{HCO}_{3}^{-} \\
\left(\mathrm{g} \cdot \mathrm{L}^{-1}\right)\end{array}$ & $\begin{array}{l}\mathrm{NaCl} \\
\left(\mathrm{g} \cdot \mathrm{L}^{-1}\right)\end{array}$ & $\begin{array}{c}\mathrm{N}-\mathrm{NH}_{3} \\
\left(\mathrm{mg} \cdot \mathrm{L}^{-1}\right)\end{array}$ & $\begin{array}{c}\mathrm{PO}_{4}^{-3} \\
\left(\mathrm{mg}^{-1} \mathrm{~L}^{-1}\right)\end{array}$ \\
\hline platensis & Suíno (10\%) & 174 & 33 & $500 \mathrm{fc}$. & $1,7-16,8$ & 0,5 & 185 & 425 \\
\hline maxima & Bovino (1\%) & 200 & 30 & Ambiente & 16 & - & - & 127 \\
\hline platensis & Suíno & 10 & 30 & Ambiente & $1-3$ & $3-7$ & 100 & - \\
\hline maxima & Suíno (2\%) & 1 & 30 & $80 \mu \mathrm{Em}^{-2} \mathrm{~s}^{-1}$ & 2 & - & - & - \\
\hline platensis & Aves (2\%) & 200 & 30 & Ambiente & 4 & 0,5 & 30 & 128 \\
\hline fusiformis & Bovino & - & 30 & Ambiente & 8 & 1 & - & 250 \\
\hline maxima & $\begin{array}{c}\text { Bovino- } \\
\text { suíno (3- } \\
4,5 \%)\end{array}$ & 300 & 22 & 3-30Lux & $1-2$ & $5-7$ & $\begin{array}{l}100- \\
1200\end{array}$ & $\begin{array}{l}100- \\
250\end{array}$ \\
\hline sp. & $\begin{array}{l}\text { Suíno } \\
(0,8 \%)\end{array}$ & 12.500 & - & Ambiente & 8,4 & 0,5 & - & 250 \\
\hline platensis & Suíno (2\%) & 1 & 25 & - & 10 & - & 465 & 1,7 \\
\hline maxima & Suíno (2\%) & 2 & Ambiente & 1.500 lux & 8,4 & 0,5 & 83 & 4 \\
\hline maxima & Suíno (2\%) & 20 & 30 & $70 \mu \mathrm{Em}^{-2} \mathrm{~s}^{-1}$ & 4 & $\begin{array}{c}\text { Água } \\
\text { do } \\
\text { mar }\end{array}$ & 25,2 & 13,6 \\
\hline platensis & Bovino & 0,5 & 36 & $34 \operatorname{lux}$ & $2-4$ & 0,3 & 17 & 49 \\
\hline
\end{tabular}

Fonte: LALIBERTÉ, OLGUÍN e LA NOUE (1997).

Um dos resíduos gerados pelas usinas açucareiras é o bagaço de cana-de-açúcar. Pelizer, Pontieri e Moraes (2007) desenvolveram meio de cultura sólido à base de bagaço, previamente lavado com água destilada, seco em estufa a $40^{\circ} \mathrm{C}$ por 30 horas e moído em moinho de facas de $0,5 \mathrm{~mm}$. A biomassa obtida ao final do cultivo foi de $7,17 \mathrm{~g} \cdot \mathrm{kg}^{-1}$, superior aos resultados encontrados com qualquer meio líquido. O tempo de cultivo foi praticamente $50 \%$ menor (7 dias) que o realizado em tanques, gerando produtividade de $1,17 \mathrm{~g} \cdot \mathrm{kg}^{-1}$.

O efluente de fábrica de macarrão elaborado com farinha de arroz (rico em carbonato, bicarbonato, nitratos, fosfatos, cloreto de sódio, cálcio e magnésio) foi avaliado quanto a sua capacidade de cultivo de A. platensis. Sua aplicação ocorreu mediante tratamento prévio de decantação e filtração de partículas e posterior diluição de 1:11 em água de rede. Em seguida, foi suplementado com 0,09 g. $\mathrm{L}^{-1}$ de nitrato, $0,59 \mathrm{~g} \cdot \mathrm{L}^{-1}$ de fosfato, $0,18 \mathrm{~g} \cdot \mathrm{L}^{-1}$ de potássio e $3 \mathrm{~g} \cdot \mathrm{L}^{-1}$ de bicarbonato de sódio. A composição química da biomassa mostrou-se similar a obtida sob cultivo no meio de Zarrouk, porém a produtividade foi baixa $\left(0,59{\left.\mathrm{~g} \cdot \mathrm{L}^{-1}\right)}^{-1}\right.$ (VETAYASUPORN, 2004)

\section{CONCLUSÃO}

O emprego de ampla variedade de fontes de nutrientes de baixo custo, quando sua concentração é ajustada à sua taxa de utilização por $A$. platensis, apresenta grande potencial de produção dessa microalga gerando resultados satisfatórios em relação a meios de cultura sintéticos, de composição definida.

Bases alternativas tais como, água do mar, água doce e diversos outros resíduos também podem ser empregados com eficiência.

Como a composição bioquímica das microalgas varia em função da disponibilidade de nutrientes e das condições de cultivo torna-se necessário verificar se a composição bioquímica da biomassa obtida enquadra-se nas características requeridas segundo a aplicação desejada. 


\section{ABSTRACT \\ ALTERNATIVE NUTRIENTS SOURCES FOR Arthorpira (Spirulina) spp. CULTIVATION}

The objective of the present literature review was to collect information about alternative nutrients sources for Arthrospira (Spirulina) cultivation using low cost basis, since the culture medium represents significant part of this microalgae production costs. Because of the microalgae uptake of nitrates and phosphates that are present in several kinds of wastes, these alternatives also results in environmental benefits. It was concluded that a large range of alternative nutrients sources were efficient. Although to avoid productivity loss each new nutrient source must be adjusted to reach the concentration in which occurs the highest growth rate and maximum cell concentration, and wastes must also have their lack or excess of nutrients corrected.

KEY-WORDS: Arthrospira (Spirulina); CARBON SOURCES; NITROGEN SOURCES; LOW-COST PRODUCTION.

\section{REFERÊNCIAS}

1 ANAGA, A.; ABU, G.O. A laboratory-scale cultivation of Chlorella and Spirulina using waste effluent from a fertilizer company in Nigeria. Bioresource Technology, v. 58, n. 1, p. 93-95, 1996.

2 ANDRADE, M.R.; COSTA, J.A.V. Mixotrophic cultivation of microalga Spirulina platensis using molasses as organic substrate. Aquaculture, v. 264, n. 1-4, p. 130-134, 2007.

3 ANDRADE, M.R.; COSTA, J.A.V. Culture of microalga Spirulina platensis in alternative sources of nutrients. Ciência e Agrotecnologia, v. 32, n. 5, p. 1551-1556, 2008.

4 ARAÚJO, K.G.L.; FACCHINETTI, A.D.; SANTOS, C.P. Influência da ingestão de biomassa de Spirulina (Arthrospira sp.) sobre o peso corporal e consumo de ração em ratos. Ciência e Tecnologia de Alimentos, v. 23, n. 1, p. 6-9, 2003.

5 BECKER, W. Microalgae in human and animal nutrition. In: RICHMOND, A. Handbook of microalgal culture: biotechnology and applied phycology. Londres: Blackwell Science, 2004. p. 312-351.

6 BERTOLDI, F.C.; SANT'ANNA, E.S.; OLIVEIRA, J.L.B. Revisão: biotecnologia de microalgas. Boletim do CEPPA, v. 26 , n. 1 , p. 9-20.

7 BERTOLIN, T.B.P.; COSTA, J.A.V.; BERTOLIN, T.E.; COLLA, L.M.; HEMKEMEIER, M. Cultivo da cianobactéria Spirulina platensis a partir de efluente sintético de suíno. Ciência e Agrotecnologia, v. 29, n. 1, p. 118-125, 2005.

8 CAMACHO, A.; WIT, R. Effect of nitrogen and phosphorus additions on a benthic microbial mat from a hypersaline lake. Aquatic Microbial Ecology, v. 32, p. 261-273, 2003.

9 CAÑIZARES, R.O.; DOMINGUEZ, A.R. Growth of Spirulina maxima on swine waste. Bioresource Technology, v. 45, n. 1, p. 73-75, 1993.

10 CAÑIZARES-VILLANUEVA, R.O.; DOMÍNGUEZ, A.R.; CRUZ, M.S.; RÍOS-LEAL, E. Chemical composition of cyanobacteria grown in diluted, aerated swine wastewater. Bioresource Technology, v. 51, n. 2-3, p. 111-116, 1995

11 ÇELEKLI, A.; YAVUZATMACA, M. Predictive modeling of biomass production by Spirulina platensis as function of nitrate and $\mathrm{NaCl}$ concentrations. Bioresource Technology, v. 100, n. 5, p. 1847-1851, 2009.

12 CHEN, F.; ZHANG, Y. High cell density mixotrophic culture of Spirulina platensis on glucose for phycocyanin production using a fed-batch system. Enzyme and Microbial Technology, v. 20, n. 3, p. 221-224, 1997.

13 CHEN, T.; ZHENG, W.; WONG, Y; YANG, F; BAI, Y. Accumulation of selenium in mixotrophic culture of Spirulina platensis on glucose. Bioresource Technology, v. 97, n. 18, p. 2260-2265, 2006.

14 CHOJNACKA, K.; NOWORYTA, A. Evaluation of Spirulina sp. growth in photoautotrophic, heterotrophic and mixotrophic cultures. Enzyme and Microbial Technology, v. 34, n. 5, p. 461-465, 2004.

15 COLLA, L.M.; BERTOLIN, T.E.; COSTA, J.A.V. Fatty acids profile of Spirulina platensis grown under different temperatures and nitrogen concentrations. Zeitschrift fur Naturforschung, v. 59c, p. 55-59, 2004.

16 COLLA, L.L.; REINEHR, C.O.; REICHERT, C.; COSTA, J.A.V. Production of biomass and nutraceutical compounds by Spirulina platensis under different temperature and nitrogen regimes. Bioresource Technology, v. 98, n. 7, p. 14891493, 2007.

17 CONVERTI, A.; SCAPAZZONI, S.; LODI, A.; CARVALHO, J.C.M. Ammonium and urea removal by Spirulina platensis. Journal of Industrial Microbiology \& Biotechnology, v. 33, n. 1, p. 8-16, 2006. 
18 COSTA, J.V.; COLLA, L.; DUARTE FILHO, P.; KABKE, K.; WEBER, A. Modelling of Spirulina platensis growth in fresh water using response surface methodology. World Journal of Microbiology and Biotechnology, v. 18, n. 7, p. 603-607, 2002.

19 DANESI, E.D.G.; RANGEL-YAGUI, C.O.; CARVALHO, J.C.M.; SATO, S. An investigation of effect of replacing nitrate by urea in the growth and production of chlorophyll by Spirulina platensis. Biomass and Bioenergy, v. 23, n. 4, p. 261269, 2002.

20 DERNER, R.B. Efeito de fontes de carbono no crescimento e na composição bioquímica das microalgas Chaetoceros muelleri e Thalassiosira fluviatilis, com ênfase no teor de ácidos graxos poliinsaturados. Florianópolis, 2006. 140 f. Tese (Doutorado em Ciência de Alimentos) - Departamento de Ciência e Tecnologia de Alimentos, Universidade Federal de Santa Catarina.

21 EI-BAKY, H.H.A.; El BAZ, F.K.; El-BAROTY, G.S. Characterization of nutraceutical compounds in blue green alga Spirulina maxima. Journal of Medicinal Plants Research, v. 2, n. 10, p. 292-300, 2008.

22 FAUCHER, O.; COUPAL, B.; LEDUY, A. Utilization of seawater-urea as a culture medium for Spirulina maxima. Canadian Journal of Microbiology, v. 25, n. 6, p. 752-759, 1979.

23 FERREIRA, L.S. Estudo da intensidade luminosa no cultivo de Arthrospira (Spirulina) platensis em reator tubular utilizando sulfato de amônio como fonte de nitrogênio por processo descontínuo alimentado. São Paulo, 2008. 113 f. Dissertação (Mestrado em Ciência de Alimentos) - Faculdade de Ciências Farmacêuticas, Universidade de São Paulo.

24 FRITZMANN, C.; LÖWENBERG, J.; WINTGENS, T.; MELIN, T. State-of-the-art of reverse osmosis desalination. Desalination, v. 216, n. 1-3, p. 1-76, 2007.

25 LALIBERTÉ, G.; OLGUÍN, E.J.; LA NOUE, J. de. Mass cultivation and wastewater treatment using Spirulina. In: VONSHAK, A. Spirulina platensis (Arthrospira): physiology, cell-biology and biotechnology. Londres: Taylor \& Francis, 1997. p. 153-159

26 LODI, A.; BINAGHI, L.; de FAVERI, D.; CARVALHO, J.C.M; CONVERTI, A.; DEL BORGHI, M. Fed-batch mixotrophic cultivation of Arthrospira (Spirulina) platensis (Cyanophycea) with carbon source pulse feeding. Annals of Microbiology, v. 55, n. 3, p. 181-185, 2005.

27 LOURENÇO, S.O. Cultivo de microalgas marinhas: princípios e aplicações. São Carlos: RiMa, 2006. 606 p.

28 MANABE, E.; HIRANO, M.; TAKANO, H.; ISHIKAWA-DOI, N.; SODE, K.; MATSUNAGA, T. Influence of ammonium chloride on growth and fatty acid production by Spirulina platensis. Applied Biochemistry and Biotechnology, v. 34-35, n. 1, 1992.

29 MATSUDO, M.C. Cultivo de Spirulina platensis por processo descontínuo alimentado repetitivo utilizando uréia como fonte de nitrogênio. São Paulo, 2006. 103 f. Dissertação (Mestrado em Ciência de Alimentos) Faculdade de Ciências Farmacêuticas, Universidade de São Paulo.

30 MATSUDO, M.C.; BEZERRA, R.P.; SATO, S.; PEREGO, P.; CONVERTI, A.; CARVALHO, J.C.M. Repeated fed-batch cultivation of Arthrospira (Spirulina) platensis using urea as nitrogen source. Biochemical Engineering Journal, $v$. 43 , n. 1, p. 52-57, 2009.

31 MITCHELL, S.A.; RICHMOND, A. Optimization of a growth medium for Spirulina based on cattle waste. Biological Wastes, v. 25, n. 1, p. 41-50, 1988.

32 MOJAAT, M.; PRUVOST, J.; FOUCAULT, A.; LEGRAND, J. Effect of organic carbon sources and Fe2+ ions on growth and ${ }^{2}$-car. Biochemical Engineering Journal, v. 39, n. 1, p. 177-184, 2008.

33 MULITERNO, A.; MOSELE, P.C.; COSTA, J.A.V.; HEMKEMEIER, M.; BERTOLIN, T.E.; COLLA, L.M. Cultivo mixotrófico da microalga Spirulina platensis em batelada alimentada. Ciência e Agrotecnologia, v. 29, n. 6, p. 1132-1138, 2005

34 OLguín, E.J.; GALICIA, S.; ANGULO-GUERRERO, O.; HERNÁNDEZ, E. The effect of low light flux and nitrogen deficiency on the chemical composition of Spirulina sp. (Arthrospira) grown on digested pig waste. Bioresource Technology, v. 77, n. 1, p. 19-24, 2001.

35 Olguín, E.J.; GALICIA, S.; CAMACHO, R.; MERCADO, G.; PÉREZ, T.J. Production of Spirulina sp. in sea water supplemented with anaerobic effluents in outdoor raceways under temperate climatic conditions. Applied Microbiology and Biotechnology, v. 48, n. 2, p. 242-247, 1997.

36 OLGUÍN, E.J.; GALICIA, S.; MERCADO, G.; PEREZ, T. Annual productivity of Spirulina (Arthrospira) and nutrient removal in a pig wastewater recycling process under tropical conditions. Journal of Applied Phycology, v. 15, $n$. 2-3, p. 249-257, 2003

37 PELIZER, L.H.; PONTIERI, M.H.; MORAES, I.O. Utilização de resíduos agro-industriais em processos biotecnológicos como perspectiva de redução de impacto ambiental. Journal of Technology Management \& Innovation, v. 2, n. 1, p. 118-127, 2007. 
38 PULZ, O.; GROSS, W. Valuable products from biotechnology of microalgae. Applied Microbiology Biotechnology, v. 65, n. 6, p. $635-648,2004$.

39 RANGEL-YAGUI, C.O.; DANESI, E.D.G.; CARVALHO, J.C.M.; SATO, S. Chlorophyll production from Spirulina platensis: cultivation with urea addition by fed-batch process. Bioresource Technology, v. 92, n. 2, p. 133-141, 2004.

40 RAOOF, B.; KAUSHIK, B.D.; REINHER, R.P. Formulation of a low-cost medium for mass production of Spirulina. Biomass and Bioenergy, v. 30, n. 6, p. 537-542, 2006.

41 REINEHR, C.O.; COSTA, J.A.V. Repeated batch cultivation of the microalga Spirulina platensis. World Journal of Microbiology and Biotechnology, v. 22, n. 9, p. 937-943, 2006.

42 RONDA, S.R.; LELE, S.S. Culture conditions stimulating high ${ }^{3}$-linolenic acid accumulation by Spirulina platensis. Brazilian Journal of Microbiology, v. 39, p. 693-697, 2008.

43 SASSANO, C.E.N.; GIOIELLI, L.A.; ALMEIDA, K.A.; SATO, S.; PEREGO, P.; CONVERTI, A.; CARVALHO, J.C.M. Cultivation of Spirulina platensis by continuous process using ammonium chloride as nitrogen source. Biomass and Bioenergy, v. 31, n. 8 , p. $593-598,2007$

44 SOLETTO, D.; BINAGHI, L.; LODI, A.; CARVALHO, J.C.M.; CONVERTI, A. Batch and fed-batch cultivations of Spirulina platensis using ammonium sulphate and urea as nitrogen sources. Aquaculture, v. 243, n. 1-4, p. 217-224, 2005.

45 SOLETTO, D.; BINAGHI, L.; FERRARI, L.; LODI, A.; CARVALHO, J.C.M.; ZILLI, M.; CONVERTI, A. Effects of carbon dioxide feeding rate and light intensity on the fed-batch pulse-feeding cultivation of Spirulina platensis in helical photobioreactor. Biochemical Engineering Journal, v. 39, n. 2, p. 369-375, 2008.

46 TREDICI, M.R.; PAPUZZO, T.; TOMASELLI, L. Outdoor mass culture of Spirulina maxima in sea-water. Applied Microbiology and Biotechnology, v. 24, n. 1, p. 47-50, 1986.

47 VETAYASUPORN, S. The potential for using wastewater from household scale fermented Thai Rice noodle factories for cultivating Spirulina platensis. Pakistan Journal of Biological Sciences, v. 7, n. 9, p. 1554-1558, 2004.

48 VOLKMANN, H.; IMIANOVSKY, U.; OLIVEIRA, J.L.B.; SANT'ANNA, E.S. Cultivo de Arthrospira (Spirulina) platensis em rejeito de dessalinizador e meio sintético salinizado: teor protéico e perfil de aminoácidos. Brazilian Journal of Microbiology, v. 39, n. 1, p. 98-101, 2008. 